\title{
Um jogo educativo para formação do Psicólogo Escolar: elaboração de um dispositivo lúdico
}

Fernando Teles - PPGIE/UFRGS - nandotelles@yahoo.com

Glauber de Freitas Benigno - UFSJ - glauberbenigno@gmail.com

Vinicius de Almeida Guanais - UFSJ-viniciusguanais@gmail.com

Larissa Medeiros Marinho dos Santos - DPSIC/UFSJ - larissa@ufsj.edu.br

Cleci Maraschin - PPGIE/UFRGS - cleci.maraschin@ufrgs.br

Dener Luiz da Silva - DPSIC/UFSJ - densilva@ufsj.edu.br

Resumo: O artigo expõe a proposta de criação de um jogo eletrônico como ferramenta de aprendizagem para a disciplina de Psicologia Escolar e Educacional e discute as possibilidades do uso de vídeo games em sala de aula. $\mathrm{O}$ jogo apresentado tem como objetivo simular atividades de uma escola, proporcionando uma vivência da prática do psicólogo escolar. Esta iniciativa baseia-se em princípios de ensino ancorados às práticas cognitivas deflagradas pelo uso crescente dos jogos eletrônicos no mundo contemporâneo. Argumentamos que, para a educação, as simulações dos vídeo games podem aproximar teoria e prática, o que propiciaria, ao aluno, condições para experimentar um modo de pensar e agir de acordo com o lhe é esperado dentro de seu campo de estudos.

Palavras chave: jogo educativo, psicologia escolar, atuação do psicólogo.

An educational video game for teaching School Psychology: development of a ludic tool

Abstract: This paper describes a video game project for teaching School Psychology, and discusses the benefits of using games in education. The game under development is aimed at simulating a school environment, by providing means through which one can practice the knowledge of the psychological work in school settings. Such initiative is based on educational principles regarding cognitive ecologies set forth by the increasing usage of video games in contemporary world. We argue that, as educational tools, video game simulations can narrow the gap between theory and practice, which could offer students a timely opportunity to experiment a way of thinking and acting in accordance to what is required in a field of knowledge.

Key-words: educational game, school psychology, psychologist's practice.

\section{Introdução}

Neste artigo, apresentamos a proposta de criação de um jogo como ferramenta de aprendizagem na formação dos psicólogos escolares. A disciplina Psicologia Escolar e Educacional, tal qual é lecionada no Departamento de Psicologia da Universidade Federal de São João del-Rei (UFSJ), recorre a estágios de observação e intervenção em instituições de ensino (preferencialmente públicas) para a formação acadêmica discente. Nessas práticas, o aluno/estagiário é exposto às problemáticas concretas que giram em torno do fenômeno escola e o modo como elas operam na produção de subjetividade. Para tanto, exige-se um acordo e contrato entre universidade e as instituições de ensino para que se possam efetivar as observações e as intervenções. 
Diante dessa experiência formativa, encontramos dois problemas que a construção de um jogo educativo sobre o trabalho do psicólogo escolar poderia nos ajudar a minimizar. Um deles diz respeito ao fato de que o relacionamento entre Universidade e Escola é cada vez mais dificultado pela expressão de um sentimento de saturação por parte das instituições de ensino que se dispõem como frequênte objeto de estudo. Consequentemente, o acesso dos alunos às escolas para a realização de práticas de estágio supervisionado vem sendo dificultado.

Além disso, a entrada do estagiário nas instituições é uma ocasião que exige preparo, pois trata-se do momento em que o aluno precisa articular conhecimentos teóricos com a prática de uma profissão. A proposta de construção de um jogo pode ser uma oportunidade de minimizar os problemas que apresentamos na oferta de um ambiente de simulação das condições de uma escola. Com base nisso, apostamos no uso de um jogo eletrônico como uma forma de organizar didaticamente a complexa operatividade de uma instituição de ensino e como um meio oportuno de propiciar e investigar como ocorre a aprendizagem das habilidades esperadas para um psicólogo escolar.

\section{Jogos na educação: soluções para um novo tipo de aprendiz}

Conforme Juul (2003; Ranhel, 2009), em geral, um jogo baseia-se em regras fixas, possui consequências negociáveis, resultados variáveis e passíveis de quantificação, além de ensejar uma atividade em que o jogador empenha determinado esforço e valoriza o resultado, a ponto de poder valorar seu desempenho. A enumeração de tais aspectos, segundo Ranhel (2009), poderá ser compatível com o modo como os jogos computacionais dão suporte à experiência do jogar. Trata-se de considerar que os games são eficazes em operar em um espaço de regras estabelecido. Além disso, automatizam a quantificação dos resultados, possuem diferentes modos de valorização do esforço e suscitam um comprometimento do jogador consigo mesmo. Para fins educativos, acrescentaríamos ainda que os jogos eletrônicos também atenderiam ao critério que estabelece a livre negociação de suas consequências para seus usuários. Como exemplo, pontos originados com a realização bem sucedida de tarefas de uma fase poderão ser convertidos em notas de uma avaliação em sala de aula, ou simplesmente servir como ponto de partida para novas etapas no processo de aprendizagem estruturado em um programa didático.

No campo da educação, a proposta de uso dos jogos eletrônicos ganha o nome de serious games (Michael e Chen, 2006; Mattar, 2010). Apesar do título, segundo Mattar (2010), trata-se de games em que um conteúdo a ser ensinado é tratado de modo leve e informal. O componente ao qual se atribui seriedade nestes jogos com o referido termo serious, diz respeito ao objetivo educativo que se deseja enfatizar (Michael e Chen, 2006). Embora o conceito de jogos sérios pareça traduzir um interesse moral em contrapor educação e brincadeira, tais games seriam diferentes das simulações educacionais: propostas mais rígidas para treinamento de um tipo de habilidade. Nesta categoria, encontram-se os simuladores de vôo utilizados por pilotos aprendizes e os simuladores de campo de batalha empregados no treinamento de soldados (Mattar, 2010).

Um outro conceito próximo a essas discussões surge sob o título de jogos epistêmicos. Em Shaffer e Gee (2006), esse conceito abrange aqueles jogos que são elaborados na intenção de desenvolver o pensamento para a inovação em uma atividade profissional. Trata-se de softwares que procuram provocar um posicionamento diferenciado diante de uma realidade profissional. 
Por outro lado, é o apelo exercido pelos jogos comerciais como um fenômeno cultural que fundamenta o entusiasmo de alguns pesquisadores pelo emprego destas mídias na educação. Um dos aspectos de aprendizagem que está presente nesses jogos é o aumento gradativo do grau de dificuldade ou complexidade na interação com determinado problema, a ponto de o jogador se sentir proficiente em uma tarefa ou desafio, e só então ser promovido para uma tarefa mais difícil (Gee, 2009).

Evidenciamos aqui uma característica fundamental que permite incluir os jogos computacionais como ferramentas de aprendizagem alinhados às práticas cognitivas da era da informática (Lévy, 1993). Ao empreendermos uma revisão bibliográfica, observamos que eles participam de um movimento transformador dos modos de pensamento e produção de subjetividade, situando-se como formas privilegiadas de tecnologia intelectual. $\mathrm{O}$ uso regular destas tecnologias pelas pessoas tem instaurado novas pautas de ação e cognição, enquanto o ensino institucional de qualquer nível não permanece indiferente à sua presença, uma vez que começam a participar da formação cultural do mundo contemporâneo (Lévy, 1993; Mattar, 2010; Shaffer et al, 2005). Por outro lado, a educação tradicional ainda se vê diante da necessidade de ser reinventada para assimilar suas potencialidades (Maraschin \& Axt, 2005).

Já para o pesquisador João Mattar (2010), a formação dos jovens na contemporaneidade padece da cisão entre as tradicionais formas institucionalizadas de transmissão do conhecimento, em que os conteúdos curriculares são apresentados de forma descontextualizada, e aquelas que ocorrem nas simulações dos vídeo games, muitas vezes construídas coletivamente e orientadas por um contexto prático e de experimentação. Diante disso, as antigas formas de avaliação ainda em uso, por exemplo, ao exigirem a correta apresentação de termos memorizados como critério de aprovação, estariam desenvolvendo apenas a habilidade de se decorar palavras para o cumprimento de uma formalidade institucional, com menos sentido a cada dia.

Um dos desafios atuais para a educação, segundo Mattar (Idem), seria resolver o conflito entre a geração que cresceu jogando vídeo games e aquela que se deparou com a tecnologia informacional na idade adulta, e que por acaso são professores da primeira. O projeto New Media Literacies (Jenkins, 2006), do Massachussetts Institute of Techology (MIT) sugere que a participação do jovem nas práticas culturais da atualidade deve observar o desenvolvimento de habilidades específicas suscitadas pelo contato com as tecnologias informacionais. Entre elas, está a resolução de problemas a partir da exploração do ambiente, traduzida por Mattar (2010) como "espírito de jogador". Na tradução de Mattar (2010) ainda encontramos "a habilidade de interpretar e criar representação de dados para exprimir ideias, encontrar padrões e identificar tendências". Trata-se de habilidades adquiridas informalmente pelos jovens que acessam a Internet, fazem trafegar informações entre seus pares, produzem conteúdo e se organizam diante da realidade e do conhecimento com uma autonomia peculiar e distante dos paradigmas ainda vigentes na educação.

Tais transformações, porém, não se restringem ao universo infanto-juvenil. Abrangem, ao invés disso, uma gama mais ampla de indivíduos, incluindo aqueles que frequentam o ensino superior ou que já estejam inseridos no mercado de trabalho e ainda se encontram diante de formas tradicionais de ensino-aprendizagem (Mattar, 2010). E é por esse motivo que a proposta do uso de um vídeo game na educação nos surge como uma ferramenta controversa e, por isso mesmo, relevante para uma investigação científica.

Como acréscimo, Shaffer et al (2005), afirmam que os vídeo games não constituem apenas um brinquedo, um produto lucrativo de uma indústria bilionária ou um mero atalho para alfabetização digital. Seu principal apelo está no fato de 
permitirem a criação e participação em mundos inéditos. Na educação, eles podem dissolver a dicotomia entre a teoria e a prática, já que oportunizam experiências que, no ensino formal institucionalizado, é algo inexistente ou subordinado à predominância da transmissão de símbolos e palavras. Segundo os mesmos autores (Shaffer et al, 2005), o potencial dos mundos virtuais criados pelos vídeo games elicia a compreensão situada, ou seja, torna possível o entendimento de conceitos com relativo nível de complexidade e mantém a tensão entre a abstração e a experimentação. Além disso, os games expandem ou generalizam seus efeitos para outros contextos, transformando-se em temas de discussão extra-classe, em tópicos de fóruns na Internet, em sites especializados, em comunidades virtuais e em meios de divulgação impressa. Com isso, os autores procuram demonstrar o quanto os jogos são capazes de nutrir o exercício do conhecimento na vida dos jogadores para além do que poderia fazer o currículo institucional da educação formal.

Tais considerações nos fazem refletir sobre como os jogos participam da apropriação do conhecimento em interação com um aluno. Segundo Tonéis (2010), a emoção produzida pelos jogos enseja a sensibilização necessária para o interesse pela descoberta e pelo conhecimento. E, de acordo com Brandão et al (2010), eles realizam imaginações, transcendendo a concretude e o imediatismo da vida, expandindo a disposição conceitual e subjetiva do jogador.

Neste sentido, acreditamos que preparar um jogo educativo equivaleria a deslocar o foco da organização do material didático para as necessidades e capacidades do aluno. Uma vez que um vídeo game pode ser jogado repetidas vezes e de acordo com a adaptação do jogador às tarefas propostas, o desenvolvimento e apreensão do conteúdo se fazem em um ritmo próprio, em que a avaliação é constante e inerente ao mecanismo do jogo.

\section{Um jogo para a formação do psicólogo escolar e educacional}

A partir de tais considerações, procuramos elaborar um jogo para simular os problemas que interessam ao psicólogo escolar e educacional. O gameplay ${ }^{1}$ baseia-se na construção de um diagnóstico a partir de vestígios, discursos e outros eventos que surgem como expressão dos fenômenos de interesse em estudos de caso.

Segundo o Conselho Federal de Psicologia (2000), as atividades do psicólogo escolar abrangem a condução de "pesquisa, diagnóstico e intervenção, preventiva ou corretiva, em grupo ou individualmente, envolvendo todos os segmentos do sistema que participam do processo de ensino-aprendizagem". Além disso, esse profissional observa e intervém no funcionamento institucional, atua junto a professores e demais profissionais da escola no intuito de elaborar, implementar, avaliar e reformular currículos, propostas e políticas pedagógicas e desenvolver programas educacionais.

Esta visão geral da atuação do psicólogo nas instituições de ensino tem guiado os passos de nosso trabalho de transpor eventos desta profissão em um game. A proposta de construção do mesmo está em andamento desde abril de 2010 e faz parte do conjunto de atividades desenvolvidas por integrantes do Laboratório de Pesquisa e Intervenção Psicossocial da UFSJ, LAPIP/UFSJ e de uma pesquisa em nível de doutorado conduzida por Fernando Teles, aluno do Programa de Pós-Gradução em Informática na Educação da UFRGS. Nosso produto final será um game educativo destinado à formação do profissional em Psicologia Escolar e Educacional e será um instrumento de investigação em pesquisas acerca das modalidades de atuação desse profissional. 
Na produção do game, temos utilizado o Adobe Flash CS4, escolhido pela facilidade oferecida pelas condições de programação da mecânica do jogo e na ilustração de elementos em $2 \mathrm{D}$, tais como os personagens e o ambiente geral do software. O jogo funcionará em uma plataforma de servidor on-line, com acesso restrito a alunos e professores mediante senha.

As problematizações do game serão estruturadas baseando-se em estudos de caso da literatura produzida no campo da Psicologia Escolar e Educacional. O software será disponibilizado com uma configuração padrão, tratando de um tema específico como o da violência escolar. No entanto, os casos referentes ao tema, poderão ser alterados por cada professor na elaboração das fases de diagnóstico e intervenção. Os professores terão um painel de controle onde poderão configurar uma sessão de jogo, personalizando os itens de diagnóstico e as intervenções relacionadas a cada item. Além disso, poderão cadastrar e emitir convites aos alunos que irão participar e ter acesso aos dados referentes à utilização. As configurações efetuadas pelos professores ficarão disponíveis na forma de sugestão para outros professores. Dessa forma, haverá conteúdo de discussão sobre os assuntos tratados.

Assim que iniciar o jogo, uma tela de boas vindas será apresentada para que o jogador caracterize seu personagem. Ele também será capaz de definir detalhes como o tipo de cabelo e a cor da pele de seu avatar, possibilitando uma construção lúdica.

Após essa etapa, o jogador, já imbuído de seu avatar de psicólogo escolar, será enviado para a sala da diretora, onde conhecerá as demandas explícitas para as quais deverá apresentar uma solução. Em seguida, deixará a sala da diretora e deverá começar a procurar por pistas (itens de diagnóstico) que indiquem uma possível solução para o problema que está acontecendo naquela instituição, com a finalidade de apresentar um diagnóstico e uma intervenção adequados.

Essas pistas surgirão como elementos clicáveis e espalhados pelo cenário. Elas podem ser objetos, alunos, professores, funcionários ou documentos. Esses elementos poderão apresentar seu conteúdo de diferentes formas, que incluem animações, sons e textos, representativos ou não, de uma das características do problema a ser resolvido. Cada um desses elementos encontrados poderá ter ou não relevância para uma hipótese diagnóstica, dessa forma a escola poderá apresentar uma complexidade próxima ao que é observado nas instituições concretas. Portanto, o jogo oferecerá condições para que o jogador se esforce em estabelecer relações coerentes, em detrimento da aparente desordem entre elementos mais e menos significativos para um diagnóstico.

$\mathrm{Na}$ medida em que realiza uma leitura crítica das pistas encontradas, o jogador poderá observar seu progresso acompanhando a ativação de botões dispostos em uma barra horizontal no topo da tela. Para cada pista encontrada, um desses botões é ativado, mudando sua cor e indicando ao jogador o que foi revelado e o que ainda está para ser. Caso sinta necessidade, o jogador poderá rever seu histórico de pistas reveladas, clicando nesses botões já ativados para ver novamente cada uma delas e repensar a construção de suas hipóteses.

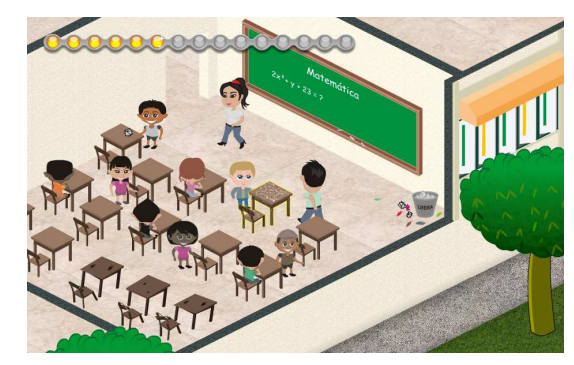

Figura 1 - Psicólogo, professora e alunos em uma sala de aula. 
Assim que terminar, ele deverá apresentar uma hipótese de diagnóstico e uma intervenção ao caso. Para tanto, será apresentada uma tela onde ele indicará o problema encontrado e uma solução possível. Nessa etapa, o jogador contará com uma "caixa de ferramentas" do psicólogo escolar. Nela, estarão presentes modalidades comuns de intervenções utilizadas pelo psicólogo de modo geral, não se limitando àquelas comuns à prática da Psicologia Escolar e Educacional. A ideia aqui é, inclusive, deflagrar mais reflexões sobre o que é adequado ou não a determinados casos e situações de intervenção.

Dentro dessa "caixa de ferramentas" poderá haver intervenções como dinâmicas de grupo, atendimentos individuais ou em grupo, solicitação de serviços à diretoria, mudanças específicas em algum elemento da rotina da escola, entre outros. É importante salientar que, dependendo do problema, o psicólogo poderá escolher sobre qual dimensão da realidade social sua intervenção deverá incidir. E isso poderá incluir esferas como a família, a associação de moradores do bairro, só o corpo docente, só os discentes, só os funcionários ou, em determinadas ocasiões, uma mesclagem sistemática desses grupos.

A qualidade do diagnóstico e da intervenção será determinada caso a caso, ponderando-se a fase atual do jogo (inicial, intermediária ou avançada) a fim de definir o nível de exigência na avaliação do desempenho do jogador. Uma boa pontuação será requerida a cada etapa ou nível, para que o jogador avance para a execução do diagnóstico seguinte.

Por fim, ao concluir o diagnóstico, o jogador poderá visualizar seu desempenho em um relatório detalhado sobre seus movimentos no jogo. Os passos seguidos para a visualização das pistas, os ambientes da escola que foram visitados, as esferas sociais acessadas para a realização do diagnóstico, entre outras coisas estarão dispostas em uma série temporal para que o aluno tome consciência dos passos que seguiu. Esses dados poderão ser utilizados pelo professor para travar discussões em sala de aula com seus alunos. Em tais momentos, os alunos poderão ser ouvidos e instigados a falar sobre o que o jogo apresenta de relevante para a prática profissional.

Como instrumento educativo, acreditamos que o uso deste jogo em sala de aula será um recurso a mais para que o professor promova sessões interessantes de aprendizagem entre seus alunos. Simultaneamente, tentamos articular a construção do jogo com práticas educativas inspiradas nos estudos que tematizam os jogos na educação. Com base em Gee (2009), apresentamos a seguir alguns princípios que nos orientam no decorrer do desenvolvimento do referido software.

Identidade. Segundo Gee (2009), os bons vídeo games são eficazes em oferecer identidades das quais os jogadores possam se apropriar durante o processo de aprendizagem. Assumir o controle de um avatar com o qual o jogador poderá experimentar desafios e missões durante o jogo, poderá equivaler a um tipo de comprometimento com aquele personagem específico. Acreditamos que o mesmo poderá ocorrer com o estudante de psicologia que se disponha a comandar ações personalizadas por seu avatar e verificar suas consequências em um jogo eletrônico.

Interação. A vantagem de se aprender com um jogo é que a relevância de cada ação do jogador é apresentada em resposta às suas ações. Para cada ato possível realizado para o cumprimento de tarefas, há efeitos situados que exigem reposicionamento constante do jogador. $\mathrm{O}$ conhecimento e a compreensão surgem da interação, no momento em que se atribui sentido ao modo de funcionamento da simulação. No caso da aprendizagem das habilidades requeridas ao psicólogo escolar, este princípio está na base da própria proposição do jogo como ferramenta educativa. 
Ao interagir com os fenômenos apresentados pela teoria exposta em sala de aula, o aluno poderá testar hipóteses enquanto joga.

Produção. A cada decisão tomada pelo jogador no decorrer de uma partida, ele contribui para redefinir o cenário original. Toda ação dispara outra, que altera um estado de coisas e especifica possibilidades. No uso do jogo do psicólogo escolar em sala de aula, estes efeitos ainda poderão deflagrar outras histórias não previstas no cenário do jogo, ensejando discussões mais aprofundadas com base nos problemas vividos pelo psicólogo virtual.

Riscos. Como em qualquer simulação computacional, as consequências de um erro são menores do que seria se ocorresse na realidade que lhe serve de modelo. Não importa se o jogador não estiver preparado no início de uma partida, ele sempre poderá recomeçar de novo se errar. No jogo do psicólogo, fracassar na realização de um diagnóstico poderá ser um primeiro passo para que o aluno jogador se sinta instigado a procurar por mais pistas que lhe ajude a resolver os enigmas que giram em torno de um caso. Além disso, sob a orientação de um professor, os riscos poderão ajudar o aluno a pensar em como minimizá-los quando precisar aplicar os conhecimentos no trabalho prático de uma escola real.

Customização. O modo particular de se começar a solucionar um problema durante um jogo decorre de uma organização inicial do jogador para resolvê-lo. A opção sobre por onde e como começar é algo que poderá diferir entre os aprendizes. $\mathrm{O}$ respeito a tais diferenças parece traduzir a ideia de que os currículos acadêmicos deveriam se adequar à singularidade daquele que aprende. Estas considerações nos fazem pensar que a aprendizagem do trabalho do psicólogo escolar não precisa ter como base as prescrições definidas pelo estilo de um psicólogo tutor. Ao invés disso, o jogo em sala de aula poderá servir como um laboratório, no qual o aluno poderá experimentar a validade de seu próprio caminho frente ao que aprende com a teoria e com o professor.

Agência. Os princípios listados acima contribuem para que o jogador sinta-se com uma autonomia relativa nessa experiência programada. No jogo do psicólogo escolar, esta sensação pode reforçar a responsabilidade daquele que age, além de convocar o aluno a pensar com cautela antes de agir.

Ordenação dos problemas. A possibilidade de explorar soluções para um problema pode conduzir à criação de estratégias criativas. No entanto, isso nem sempre tende a propiciar condições adequadas para a resolução de problemas subsequentes. Os jogos eletrônicos organizam a apresentação dos problemas de modo que o cumprimento de etapas iniciais seja relevante para a realização de etapas posteriores. No jogo do psicólogo escolar, esse princípio será explorado com o aumento gradual do nível de dificuldades para a realização das tarefas propostas. Como exemplo, podemos considerar que as primeiras fases podem abordar questões relativas à entrada do psicólogo na instituição, abrindo caminho para inserção de problemas de outra natureza nos próximos níveis.

Desafio e consolidação. Em um jogo eletrônico, a consolidação da aprendizagem de determinada habilidade do jogador é resultado de sua exposição frequente a uma classe de desafios. Uma vez consolidada em uma etapa inicial, essa mesma habilidade poderá ser colocada novamente à prova em etapas posteriores, incentivando o aprendiz a rever o que aprendeu até então e considerar o que mais precisa ser melhorado. O jogo do psicólogo escolar poderá se basear nesse princípio principalmente quando seu uso em sala de aula estiver articulado com o conteúdo ministrado pelo professor. $\mathrm{O}$ aumento no nível de dificuldade poderá decorrer de um acordo entre professor e aluno, conforme a necessidade por mais desafios se fizer relevante para o fluxo do processo de aprendizagem. 
Na hora certa e a pedido. A tradicional forma de aprendizagem baseada em textos é criticada por Gee (2009) como sendo um exagero que descontextualiza o conhecimento que se deseja ensinar. Em um jogo, o uso de mensagens verbais costuma ocorrer nos momentos mais propícios, ou quando o jogador precisa delas para continuar jogando. Dessa forma, a informação não é supervalorizada em detrimento da ação. No jogo do psicólogo escolar, esse recurso será utilizado como um acessório. Se o jogador sentir necessidade, poderá se aprofundar em determinado tema com referências disponibilizadas pelo professor na interface do software. Ao precisar refletir para resolver uma questão qualquer, ícones de ajuda estarão disponíveis para que o aprendiz os acione e visualize conceitos ou até mesmo sugestões de referências bibliográficas com obras que lidam teoricamente com o problema apresentado.

Sentidos contextualizados. Ao oferecer diálogos, imagens em movimento e sonorização, os games são eficazes em explicar conceitos imediatamente associados ao seu uso prático na realidade. Este aspecto produz contextualizações, algo que desaparece no ensino tradicional quando a exposição de algum assunto baseia-se no uso de palavras para explicar o sentido de outras palavras. O jogo do psicólogo escolar se apropria deste princípio na proposta de utilizar animações ilustrativas dos problemas que pretende apresentar ao jogador. Além disso, a própria estruturação de uma escola em um jogo virtual será uma forma de promover reflexões associadas a eventos nos quais o aluno toma parte como protagonista.

Frustração prazerosa. Os princípios anteriores posicionam a jogabilidade de um vídeo game na fronteira entre o que jogador consegue realizar e aquilo que ele ainda precisa aprender. Os desafios são considerados como superáveis e podem, portanto, despertar a motivação do aprendiz. Ao invés de tomar como trabalhosa demais a tarefa de aprender a ser um profissional, o aluno poderá experimentar-se ludicamente diante de problemas que interessam à sua formação.

Pensamento sistemático. Os games mobilizam a capacidade do jogador de enxergar um jogo como um sistema de relações. Diante de uma complexidade de personagens e ações, o jogador precisa tentar entender como seus próprios movimentos exercem efeitos sobre o jogo como um todo. Para a psicologia escolar, esta habilidade não é só desejável como também fundamental para que os eventos encontrados no cotidiano escolar sejam vistos em sua amplitude como fenômenos sociais e não como eventos isolados ou até mesmo individuais. No jogo do psicólogo escolar, esta habilidade poderá ser fomentada quando o jogador precisar apresentar diagnósticos e intervenções concebidas a partir da análise de vários acontecimentos e demandas.

Explorar, pensar lateralmente, repensar os objetivos. Os games incentivam o jogador a redefinir seus objetivos. Não há uma exigência imediata que o faça perseguir uma única meta até o fim da partida. $O$ jogo incentiva o pensamento lateral e não apenas o linear, tomando desvios se preciso for. $\mathrm{O}$ mesmo poderá ocorrer com o usuário do jogo do psicólogo escolar que, na necessidade de realizar sínteses sobre fenômenos dispersos na simulação da instituição escolar, poderá se orientar pela análise de eventos, personagens, demandas e os efeitos de suas próprias ações sobre eles enquanto as executa.

Ferramentas inteligentes e conhecimento distribuído. Para operar um personagem de um game, o jogador não precisa conhecer em detalhes como executar cada ação que tal personagem precisa realizar para avançar. A programação de muitos jogos permite, por exemplo, que o jogador dê comandos a um ou mais avatares e que estes cumpram a tarefa em questão sem depender de outras habilidades do jogador. Trata-se de um forma de distribuição do conhecimento entre jogador e personagens virtuais. No jogo do psicólogo escolar, este princípio poderá operar de modo semelhante 
ao nosso exemplo. Quando um jogador optar por uma intervenção após um diagnóstico, esta será aplicada pela mecânica do jogo e o aprendiz só terá acesso às suas consequências para o funcionamento da escola.

Equipes transfuncionais. Segundo Gee (2009), quando um game é jogado em versão multiplayer, as trocas sociais entre os diversos jogadores poderão deflagrar agrupamentos cooperativos em torno de missões a serem cumpridas. Em tais ocasiões, além de dominar habilidades específicas, um jogador procura conhecer minimamente as habilidades de seus pares para efetivar coordenações produtivas em trabalhos de equipe. No que diz respeito ao jogo do psicólogo escolar, acreditamos que este fenômeno poderá ser proveitoso quando decorrer da utilização do software em sala de aula. $\mathrm{O}$ modo de compreender e jogar, distinto entre os aprendizes, poderá potencializar a compreensão singular de cada um no decorrer da aprendizagem.

Performance anterior à competência. Por fim, este princípio reforça a noção de que um game pode ser uma ferramenta didática relevante para a aprendizagem dos conhecimentos de uma profissão. Os jogos eletrônicos permitem que o jogador coloque em prática habilidades que, nos moldes do ensino tradicional, só lhe seria permitido experimentar após a conclusão de sua formação educacional. Isso sugere que o jogador poderá desempenhar as funções de uma profissão, por exemplo, mesmo que ainda não possua competência acadêmica suficiente para tal, realizando interativa e virtualmente o que não poderia em função de constrangimentos éticos e disciplinares. Além disso, segundo Gee (2009), é comum que as instituições de ensino lecionem uma unidade curricular qualquer com a apresentação de textos na expectativa de produzir alunos competentes em seus campos de estudo. Por outro lado, para jogar um game, os jogadores trocam informações, ensinam e aprendem com seus pares, praticam constantemente a aquisição de novas habilidades e não separam conhecimento e prática. Com base neste princípio, o jogo do psicólogo escolar pode ser uma forma de produzir deslocamentos no fluxo de aprendizagem em sala de aula. Em meio a leituras, conceitos, discussões, entre outros, o aluno pode se valer da simulação de uma escola para refazer e elaborar perguntas acerca da realidade em estudo.

\section{Considerações finais}

O uso dos games na educação decorre de um interesse em explorar capacidades de um tipo de aluno que passou a existir com as novas práticas de participação e cognição em meio às tecnologias informacionais. A construção de um jogo para a formação do Psicólogo Escolar e Educacional é uma tentativa de aproveitarmos as consequências deste fenômeno para introduzirmos, em sala de aula, uma ferramenta que potencialize mais controvérsias no campo da Informática na Educação. Operando como um instrumento didático e de pesquisa, o jogo poderá produzir deslocamentos nos modos de ensinar e aprender a Psicologia Escolar e Educacional. Na medida em que os professores o utilizarem em suas aulas, poderemos conhecer também, como é posto em prática o ensino dos conhecimentos deste ramo da psicologia, bem como os efeitos que um jogo de simulação poderá exercer nesta atividade.

A revisão bibliográfica tem nos mostrado que é possível enxergar, no uso de jogos eletrônicos, possibilidades mais interessantes e abrangentes do que um simples fator motivacional para a aprendizagem. Destacamos o princípio apresentado por Gee (2009) que sugere que os jogos oferecem um espaço de performance para o exercício de habilidades profissionais anterior à competência formal baseada no ensino institucionalizado. Não se trata de romper com o ensino tradicional, mas de abrir mais espaço para um modo de pensar com o apoio das tecnologias informacionais, ainda 
pouco exploradas. Entre as vantagens, enfatizamos uma modalidade de aprendizagem ancorada a práticas concretas, mediadas pela ação e produção de um conhecimento contextualizado.

\section{Notas de texto}

${ }^{1}$ Gameplay refere-se às condições e modos de interação oferecidas ao jogador pelo ambiente do jogo e às reações desse ambiente em função de suas escolhas (Sato, 2008).

\section{Referências}

BRANDÃO, R. P.; Bittencourt, M. I. G. F.; Vilhena, J. A mágica do jogo e o potencial do brincar. In: Proceedings of SBGames 2010, Trilha de Games \& Cultura, Florianópolis, 2010.

CONSELHO FEDERAL DE PSICOLOGIA. Resolução $\mathbf{n}^{\mathbf{0}}$. 014/00, de 20 de dezembro de 2000. Institui o título profissional de Especialista em Psicologia e dispõe sobre normas e procedimentos para seu registro. Brasília, 2000.

GEE, J. P. Bons videogames e boa aprendizagem. Perspectiva, Florianópolis, v. 27, n. 1, 167-178, jan./jun, 2009.

JENKINS, H. Confronting the Challenges of Participatory Culture. Chicago, IL, MacArthur Foundation, 2006.

JULL, J.. The Game, the Player, the World: Looking for a Heart of Gameness. In Level Up: Digital Games Research Conference Proceedings, Utrecht: Utrecht University, (pp. 30-45), 2003. Disponível em: http://www.jesperjuul.net/text/gameplayerworld. Acesso em: 20 de mai. 2011.

LÉVY, P. As tecnologias da inteligência: o futuro do pensamento na era da informática. Editora 34, 1a Edição, 1993.

MATTAR, J. Games em educação: como os nativos digitais aprendem. São Paulo: Pearson Prentice Hall, 2010.

MARASCHIN, C.; AXT, M. Acoplamento Tecnológico e Cognição. In: VIGNERON, J.; OLIVEIRA, V.B. (Org.). Sala de Aula e Tecnologias. São Bernardo do Campo: Universidade Metodista de São Paulo, 2005, 39-51.

MICHAEL, D.; CHEN, S. Serious games: Games that educate, train, and inform. Thomson, Boston, MA, 2006.

RANHEL, J. O conceito de jogo e os jogos computacionais. In SANTAELLA, L; FEITOZA, M. (Org). Mapa do Jogo. A diversidade cultural dos games. São Paulo: Cangage Learning, p. 3-22, 2009.

SATO, A. K. O.; CARDOSO, M. V. Além do gênero: uma possibilidade para a classificação de jogos. In: Proceedings of SBGames'08, 2008.

SHAFFER, D. W.; SQUIRE, K. A.; HAVELRSON, R.; GEE, J. P. Video games and the future of learning. Phi Delta Kappan, 87(2), 104 - 111, 2005.

SHAFFER, D. W.; GEE, J. P. How computer games help children learn. Palgrave Macmillan, 2006.

TONÉIS, C. N. A lógica da descoberta nos jogos digitais. In: Proceedings of SBGames 2010, Trilha de Games \& Cultura, Florianópolis, 2010. 